\title{
Fludarabine and busulfan as a reduced-toxicity myeloablative conditioning regimen in allogeneic hematopoietic stem cell transplantation for acute leukemia patients
}

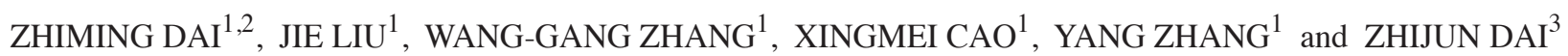 \\ Departments of ${ }^{1}$ Hematology, ${ }^{2}$ Anesthesia and ${ }^{3}$ Oncology, Second Affiliated Hospital \\ of Xi'an Jiaotong University, Xi'an, Shaanxi 710004, P.R. China
}

Received November 13, 2015; Accepted January 29, 2016

DOI: $10.3892 / \mathrm{mco} .2016 .765$

\begin{abstract}
The optimal conditioning regimen for allogeneic hematopoietic stem cell transplantation (allo-HSCT) in acute leukemia remains undefined. We evaluated the outcomes in 30 patients with acute leukemia who underwent allo-HSCT from human leukocyte antigen-matched donors after conditioning with busulfan and fludarabine (BuFlu). The regimen comprised injection of busulfan $3.2 \mathrm{mg} / \mathrm{kg}$ daily on 4 consecutive days and fludarabine $30 \mathrm{mg} / \mathrm{m}^{2}$ daily for 4 doses. All 30 patients achieved hematopoiesis reconstitution with full donor chimerism confirmed by short tandem repeat DNA analysis. The most common regimen-related toxicity was mucositis $(86.7 \%)$, followed by cytomegalovirus infection $(80 \%)$. Serious regimen-related toxicities were rare. Acute graft vs. host disease (aGVHD) was detected in $46.7 \%$ of the patients; $33.4 \%$ had grade I-II aGVHD and $13.3 \%$ had grade III-IV aGVHD. Chronic GVHD (cGVHD) was noted in $20 \%$ of the patients. The overall survival and disease-free survival rates were 66.7 and $53 \%$, respectively, with a median follow-up of 25 months for surviving patients. Therefore, BuFlu was an effective conditioning regimen with a low rate of transplant-related adverse effects and increased antileukemic effects in patients with acute leukemia undergoing allo-HSCT.
\end{abstract}

\section{Introduction}

Allogeneic hematopoietic stem cell transplantation (allo-HSCT) is considered to be a potential effective treatment strategy for patients with hematological malignancies, particularly acute leukemia. Allo-HSCT has been shown to cure leukemia via a graft vs. leukemia (GVL) effect mediated by immunological cells (1). Currently, high-dose busulfan

Correspondence to: Dr Wang-Gang Zhang, Department of Hematology, Second Affiliated Hospital of Xi'an Jiaotong University, 157 West 5th Road, Xi'an, Shaanxi 710004, P.R. China E-mail: zhangwanggang2003@yahoo.com

Key words: allogeneic hematopoietic stem cell transplantation, fludarabine, acute leukemia plus cyclophosphamide (BuCy) has been widely used as a myeloablative conditioning regimen for HSCT. Although $\mathrm{BuCy}$ is generally well-tolerated, high exposure to cyclophosphamide metabolites after HSCT may cause serious adverse events and an increase in non-relapse mortality, particularly in elderly patients. By reducing the toxicity, reduced-intensity conditioning (RIC) allows the extension of allo-HSCT to a significantly wider patient population; however, RIC is associated with an increased risk of relapse following $\operatorname{HSCT}(2,3)$.

Fludarabine may inhibit lymphocyte proliferation and promote lymphocyte apoptosis by affecting DNA replication and repair, and is considered as the conventional therapy for chronic lymphocytic leukemia (4). As an immunosuppressive purine analogue, fludarabine is used in chemotherapy regimens for acute leukemia, replacing cyclophosphamide in myeloablative and non-myeloablative conditioning regimens (5-8). In addition, busulfan plus fludarabine (BuFlu) exert a synergistic effect, impairing alkylator-induced DNA damage repair. Previous studies demonstrated that fludarabine, when used in a RIC regimen, allows adequate engraftment of allogeneic hematopoietic cells to bring about immunosuppression $(9,10)$. Several clinical trials have also demonstrated that, as a myeloablative conditioning regimen, BuFlu is associated with fewer regimen-related toxicities (RRTs), a lower incidence of non-relapse mortality, and higher disease-free survival (DFS) rates compared with $\mathrm{BuCy}$ for allo-HSCT $(5,11,12)$. Fludarabine appears to be well-tolerated by patients undergoing allo-HSCT and is a feasible conditioning regimen alternative to cyclophosphamide.

Our study retrospectively analyzed the efficacy of fludarabine $30 \mathrm{mg} / \mathrm{m}^{2}$ [intravenous (i.v.) injection daily, 4 doses] and busulfan $3.2 \mathrm{mg} / \mathrm{kg}$ (i.v. daily, 4 consecutive days) as a myeloablative conditioning regimen, considering RRT, engraftment, hematological relapse/disease progression, acute and chronic graft vs. host disease (GVHD), overall survival (OS) and DFS, in 30 patients undergoing allo-HSCT for acute myeloid leukemia (AML) and acute lymphoblastic leukemia (ALL).

\section{Patients and methods}

Patient population. Between January, 2008 and January, 2013, a total of 30 patients with AML or ALL were enrolled in this 
follow-up study at the Department of Hematology and Hematopoietic Stem-cell Transplantation Center of the Second Affiliated Hospital of Xi'an Jiaotong University (Xi'an, China). The patient characteristics, status at HSCT and donor source are outlined in Table I. All the patients had a Karnofsky performance score of $\geq 70$; normal cardiac, hepatic, and renal function; and no uncontrolled bleeding or severe infection. High-risk disease status was defined as patients who were beyond the first remission, had sustained non-remission, had multiple relapses, or were chemoresistant. All the study participants provided written informed consent for the analysis of transplant outcome data.

Human leukocyte antigen (HLA) typing and engraftment. HLA genotyping was performed in the same manner as in all centers: The presence of class I antigens was tested using standard serological techniques; and class II alleles were resolved with low-resolution molecular typing using polymerase chain reaction (PCR) amplification with sequence-specific oligonucleotide primers for hybridization of amplified DNA, followed by high-resolution typing in all patients and donors. Donor-recipient pairs were considered fully matched in cases of HLA-A, HLA-B and HLA-DRB1 compatibility.

Engraftment was defined as an absolute neutrophil count of $>0.5 \times 10^{9} / 1$ on the first 3 consecutive days and a platelet count of $>20 \times 10^{9} / 1$ after at least 3 days without the need for transfusion. Chimeric status was evaluated in nuclear cells of peripheral blood $\mathrm{T}$ cells and polymorphonuclear neutrophils on days $+20,+30$ and +60 by using the short tandem repeat PCR (STR-PCR) method.

Conditioning regimens, GVHD prophylaxis and supportive care. The myeloablative conditioning regimen consisted of fludarabine $30 \mathrm{mg} / \mathrm{m}^{2}$ infused over $30 \mathrm{~min}$ daily for 4 doses (days -5 to -2 ), followed by intravenous busulfan $3.2 \mathrm{mg} / \mathrm{kg}$ of actual or adjusted ideal body weight over $4 \mathrm{~h}$ daily on 4 consecutive days (days -5 to -2). Acute GVHD (aGVHD) and chronic GVHD (cGVHD) were diagnosed and classified according to previously described clinical criteria (13-15). Depending on the donor type, transplant recipients received traditional cyclosporin A (CSA) and short-course methotrexate (MTX) (sibling donor) or CSA, MTX and mycophenolate mofetil (unrelated donor) for GVHD prophylaxis. The serum CSA concentration was maintained between 100 and $300 \mathrm{ng} / \mathrm{ml}$, and the dose was tapered off by $5 \%$ every week from day +60 to day +90 . Supportive care comprised prophylactic transfusion of platelets if platelet counts decreased to $<20 \times 10^{9} / 1$, or prophylactic transfusion of red blood cells if hemoglobin levels decreased to $<80 \mathrm{~g} / 1$.

Antimicrobial therapy and other medications per-protocol. The patients underwent HSCT treatment in rooms with a positive-pressure filtered flow. The patients were monitored for cytomegalovirus (CMV) DNA with quantitative PCR once a week from the first day of conditioning (day -6) until day +100 , and then twice a month until the discontinuation of GVHD prophylaxis. Patients positive for CMV DNA were treated with ganciclovir and/or foscarnet until two consecutive negative test results were obtained. Neutropenic fever was managed according to the Infectious Diseases Society of America Fever and Neutropenia guidelines (16). Co-trimoxazole was initiated after engraftment to prevent Pneumocystis carinii pneumonia. Prostaglandin E1 and Danshen injections were used for veno-occlusive disease (VOD) prophylaxis, beginning with the initiation of conditioning.

Statistical analysis. The day of stem cell infusion was defined as day 0. Descriptive statistics were used to describe the baseline characteristics of disease status at conditioning. Categorical variables are summarized as frequency counts and percentages, and continuous variables are summarized as median and range. DFS was defined as the time between transplantation and the earliest occurrence of relapse or death due to any cause. Cumulative incidence or survival was plotted according to the Kaplan-Meier method and the log-rank test was used to analyze differences between groups. Basic statistical data were obtained using the SPSS software package, version 17.0 (SPSS Inc., Chicago, IL, USA). A cut-off value of 0.05 indicating statistically significant differences was adopted for all statistical analyses.

\section{Results}

Engraftment. As shown in Fig. 1, patients achieved absolute neutrophil count (ANC) recovery and received platelet engraftment at 11 days (range, 7-17 days) and 13 days (range, 7-25 days), respectively. The median time to ANC recovery or platelet engraftment was not statistically different between the sibling and unrelated donor groups. Complete donor chimerism was achieved in all patients, with neutrophil count recovery being confirmed by STR-DNA detection on days $+20,+30$ and +60 .

Regimen-related toxicity. Of the 30 patients, 1 experienced hemorrhagic cystitis (HC), which was resolved by the discontinuation of drugs that may cause or aggravate $\mathrm{HC}$, and the initiation of diuretic, hemostatic and anti-infection treatment. CMV viremia was noted in 24 patients, of whom 2 developed CMV-associated interstitial pneumonia. All 24 patients received antiviral treatment with ganciclovir and foscarnet. A total of 26 patients developed mucositis, which resolved with symptomatic therapy without any serious or permanent sequelae. There was one case of cardiac toxicity with tachycardia and no reported cases of VOD or regimen-related death. Grade II, III and IV toxicities were observed in 14 (46.7\%), $8(26.7 \%)$ and $1(3.3 \%)$ patient, respectively.

GVHD. As shown in Table I and Fig. 2, 14 patients (46.7\%) experienced aGVHD. Of those, $9(13.3 \%)$ had grade II-IV aGVHD, 4 of whom succumbed due to severe rejection. cGVHD was observed in 6 patients (20\%), including $2(6.7 \%)$ with extensive cGVHD. The incidence of aGVHD did not differ significantly between the AML and ALL groups or between the sibling and unrelated donor groups.

Survival data. With a median follow-up period of 25 months (range, 2-78 months) for surviving patients, 20 of the 30 patients remained alive. A total of 4 patients succumbed to disease relapse, whereas 6 deaths were due to non-relapse causes: aGVHD $(n=4)$, uninduced epileptic seizures $(n=1)$, 
Table I. Patient characteristics $(n=30)$.

\begin{tabular}{|c|c|}
\hline Characteristics & Number $(\%)$ \\
\hline Age, years [median (range)] & $30(13-59)$ \\
\hline \multicolumn{2}{|l|}{ Gender } \\
\hline Male & $14(47.0)$ \\
\hline Female & $16(53.0)$ \\
\hline \multicolumn{2}{|c|}{ Acute myeloid leukemia $(n=15)$} \\
\hline Complete remission 1 & $8(54.0)$ \\
\hline Complete remission 2 & $5(33.0)$ \\
\hline Non-remission & $2(13.0)$ \\
\hline \multicolumn{2}{|c|}{ Acute lymphoblastic leukemia $(n=15)$} \\
\hline Complete remission 1 & $9(60.0)$ \\
\hline Complete remission 2 & $5(33.0)$ \\
\hline Non-remission & $1(7.0)$ \\
\hline \multicolumn{2}{|l|}{ Donor gender } \\
\hline Matched & $19(63.0)$ \\
\hline Mismatch & $11(37.0)$ \\
\hline \multicolumn{2}{|l|}{ Disease risk } \\
\hline Standard ${ }^{\mathrm{a}}$ & $17(57.0)$ \\
\hline High $^{\mathrm{b}}$ & $13(43.0)$ \\
\hline \multicolumn{2}{|l|}{ Donor type } \\
\hline Sibling & $18(60.0)$ \\
\hline Unrelated & $12(40.0)$ \\
\hline \multicolumn{2}{|l|}{ Stem cell source } \\
\hline Bone marrow & $4(13.0)$ \\
\hline Peripheral blood & $26(87.0)$ \\
\hline $\begin{array}{l}\text { Mononuclear cells, } \times 10^{8} / \mathrm{kg} \\
\text { [median (range)] }\end{array}$ & $8.71(0.87-15.97$ \\
\hline $\begin{array}{l}\mathrm{CD} 34^{+} \text {cells, } \mathrm{x} 10^{6} / \mathrm{kg} \\
{[\text { median (range)] }}\end{array}$ & $3.62(0.66-12.9)$ \\
\hline \multicolumn{2}{|l|}{ GVHD prophylaxis } \\
\hline $\mathrm{CSA}+\mathrm{MTX}$ & $18(60.0)$ \\
\hline $\mathrm{CSA}+\mathrm{MTX}+\mathrm{MMF}$ & $12(40.0)$ \\
\hline \multicolumn{2}{|l|}{ Acute GVHD } \\
\hline 0 & $16(53.3)$ \\
\hline $\mathrm{I}$ & $5(16.7)$ \\
\hline II & $5(16.7)$ \\
\hline III-IV & $4(13.3)$ \\
\hline Chronic GVHD & $6(20.0)$ \\
\hline Limited & $4(13.3)$ \\
\hline Extensive & $2(6.7)$ \\
\hline
\end{tabular}

aisease in first complete remission. ${ }^{\mathrm{b}}$ More advanced status than standard-risk disease. CSA, cyclosporin A; MTX, methotrexate; MMF, mycophenolate mofetil; GVHD, graft vs. host disease.

and multifactorial respiratory failure following severe pulmonary infection $(n=1)$ (Table II). The OS and DFS rates were 66.7 and $53 \%$, respectively, at the end of follow-up (Fig. 3). Three (10\%) and one (3.3\%) relapses occurred in ALL and AML patients, respectively. The median time-to-relapse was 79 days

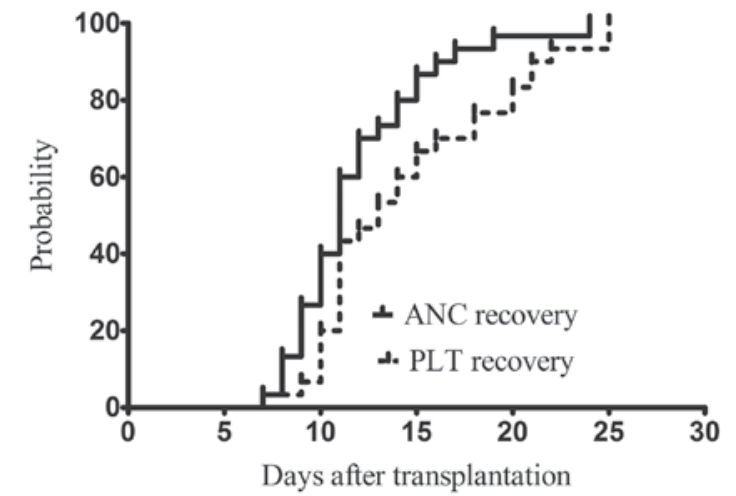

Figure 1. Cumulative incidence of absolute neutrophil count (ANC) recovery and platelet (PLT) engraftment.

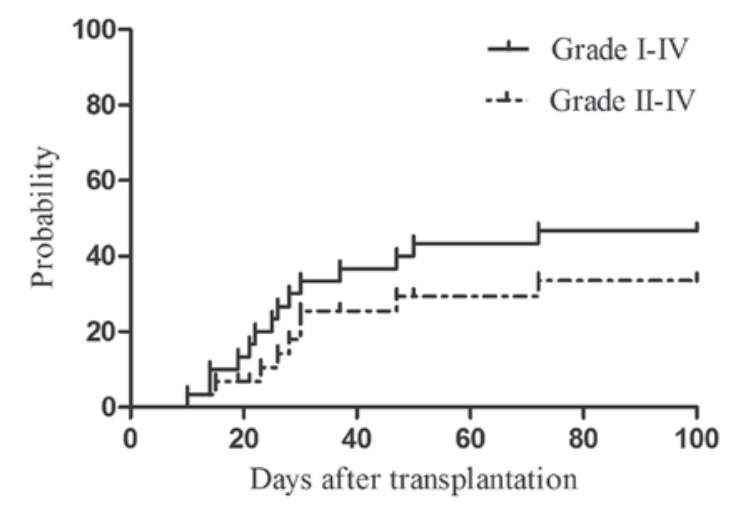

Figure 2. Cumulative incidence of acute graft vs. host disease grade I-IV vs. II-IV.

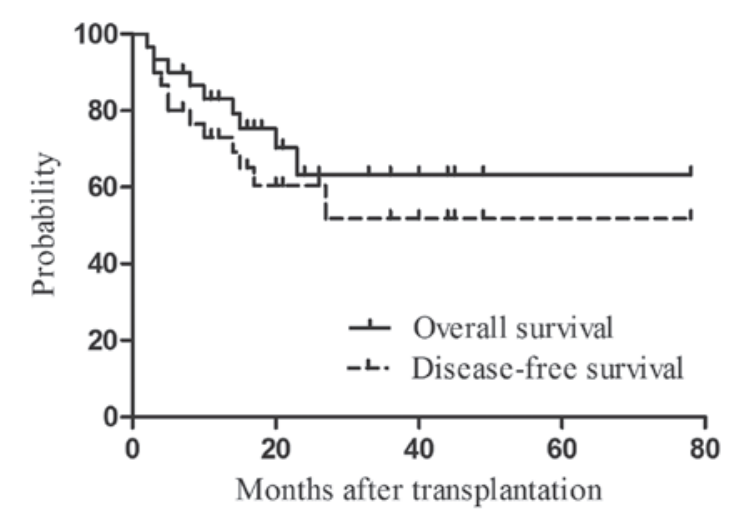

Figure 3. Kaplan-Meier curves for overall survival and disease-free survival in all patients.

(range, 65-155 days) after transplantation. The 3 patients with ALL who relapsed were chemoresistant, and the patient with AML who relapsed 155 days after transplantation was in non-remission. After receiving a full chimerism sibling donor lymphocyte infusion, the patient achieved a transient complete remission but relapsed twice and succumbed 1 year later. The probability of OS at 2 years of AML vs. ALL patients was 73.3 vs. $60 \%$, respectively, which was not statistically significant $(\mathrm{P}=0.70)$. Furthermore, the cumulative incidence rate of 2-year OS did not differ significantly between high-risk and standard-risk patients (53.8 and 76.5\%, respectively; $\mathrm{P}=0.76$ ). 
Table II. Number of deaths according to primary disease.

\begin{tabular}{|c|c|c|c|c|}
\hline Causes of death & ALL, n $(\%)^{\mathrm{a}}$ & AML, n $(\%)^{\mathrm{a}}$ & $\mathrm{HR}, \mathrm{n}(\%)^{\mathrm{a}}$ & $\mathrm{SR}, \mathrm{n}(\%)^{\mathrm{a}}$ \\
\hline Relapse-related mortality & $3(30.0)$ & $1(10.0)$ & $4(40.0)$ & $0(0.0)$ \\
\hline Non-relapse-related mortality & $3(30.0)$ & $3(30.0)$ & $2(20.0)$ & $4(40.0)$ \\
\hline GVHD & $2(20.0)$ & $2(20.0)$ & $1(10.0)$ & $3(30.0)$ \\
\hline Infection & $1(10.0)$ & $0(0.0)$ & $1(10.0)$ & $0(0.0)$ \\
\hline Other $^{\mathrm{b}}$ & $0(0.0)$ & $1(10.0)$ & $0(0.0)$ & $1(10.0)$ \\
\hline Total & $6(60.0)$ & $4(40.0)$ & $6(60.0)$ & $4(40.0)$ \\
\hline
\end{tabular}

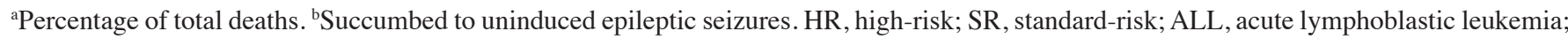
AML, acute myeloid leukemia; GVHD, graft vs. host disease.

\section{Discussion}

BuCy is a traditionally used myeloablative conditioning regimen for HLA-matched allo-HSCT. However, the high RRT due to the additive effect of the two alkylators is a major concern; in particular, cyclophosphamide metabolism is associated with sinusoidal obstruction syndrome, hemorrhagic cystitis and bilirubin level elevation, in addition to increased non-relapse mortality (17). Although a non-myeloablative transplant is associated with lower conditioning regimen-related mortality, it has a higher rate of leukemia relapse compared with a classical myeloablative transplant regimen.

The BuFlu regimen has been confirmed to be safe and effective for allo-HSCT in patients with hematological malignancies. Slavin et al (18) first reported the efficacy of fludarabine $(180 \mathrm{mg} /$ $\mathrm{m}^{2}$ ) in an RIC regimen, with an OS rate of $85 \%$ and a DFS rate of $81 \%$ after a median follow-up of 8 months for HLA-matched peripheral blood stem cell transplant. The replacement of cyclophosphamide with fludarabine appeared to decrease toxicity, while exhibiting efficacy comparable to that of $\mathrm{BuCy}$. However, the graft failure rate was higher in patients treated with the RIC regimen $(18,19)$. Other studies have demonstrated that intense conditioning may decrease the incidence of graft failure (20,21). Or et al (22) reported a 54\% rate of aGVHD with negligible toxicity after a median follow-up of 42 months with the same conditioning regimen as that used by Slavin et al (18). Bornhauser et al (23) reported that an ablative dose of BuFlu resulted in $100 \%$ engraftment and $7 \%$ RRT in 42 patients with high-risk chronic myeloid leukemia or myelodysplastic syndrome, with estimated OS and DFS rates of 42.4 and $34.9 \%$, respectively, at a median follow-up of 18 months. The MD Anderson Cancer Center reported that a regimen of fludarabine $40 \mathrm{mg} / \mathrm{m}^{2}$ and i.v. busulfan $130 \mathrm{mg} / \mathrm{m}^{2}$ once daily for 4 days was well-tolerated and effective (11). In that study, patients who received a transplant in first complete remission had 3-year OS and event-free survival rates of 78 and $74 \%$, respectively. The overall incidence of grade II-IV aGVHD was $15.8 \%$ and that of extensive cGVHD was $34.1 \%$. Thus, i.v. BuFlu was found to be a well-tolerated and efficacious myeloablative conditioning regimen with reduced toxicity. Russell et al (24) reported that high-dose fludarabine $250 \mathrm{mg} / \mathrm{m}^{2}$ and busulfan $12.8 \mathrm{mg} / \mathrm{kg}$ plus thymoglobulin was also a well-tolerated and effective regimen, with a particularly low incidence of grade III-IV aGVHD (3\%) and cGVHD (38\%) at 2 years.
In our study, we analyzed the clinical data of Chinese Han patients with acute leukemia who underwent HLA-matched allo-HSCT with the BuFlu conditioning regimen. As in most other studies, we did not observe graft failure. Neutrophil and platelet engraftment occurred on days +11 and +13 for patients who received sibling donor transplants, and on days +13 and +14 for patients who received unrelated donor transplants, respectively. There were no significant differences with the BuCy conditioning regimen regarding the time to hematopoietic reconstitution. Grade III-IV RRT was observed in $30 \%$ of the patients. The most common and serious RRTs were mucositis (86.7\%) and HC (3.3\%), respectively. CMV infection was common $(80 \%)$. Mucositis and $\mathrm{HC}$ were resolved with drug adjustment and supportive treatment. Our results were similar to those of Iravani et al (5). Grade III-IV aGVHD was detected in $13.3 \%$ of the patients, without significant differences in the incidence of aGVHD according to donor type. The rate of cGVHD in all patients (20\%) was lower compared with that observed with $\mathrm{BuCy}(25,26)$. A probable reason for this is the strong immune inhibitory effect and alkylator-induced DNA damage repair with fludarabine.

Several studies have reported an association of the BuFlu conditioning regimen with a decreased relapse rate following allo-HSCT $(27,28)$. However, other studies have reported greater relapse or progression in the BuFlu regimen arm compared with that in the BuCy arm (10). In our study, the rate of overall relapse was $30 \%$. The majority of the relapsed patients had a high risk or advanced status prior to the transplant, indicating that the rate of relapse is also associated with the pre-transplant disease status and post-transplant adjustment of immune inhibitors.

In conclusion, our study indicated that BuFlu was an acceptable regimen, due to its low rates of RRT, GVHD and morbidity in the Chinese population. BuFlu may replace $\mathrm{BuCy}$, with the aim to decrease regimen-related side effects, without compromising the efficacy. However, further comparative studies on BuFlu and standard regimens with subgroup analyses according to standard- vs. high-risk leukemia are required.

\section{Acknowledgements}

The present study was supported by the Science and Technology Foundation of Shaanxi Province, China (grant no. 2014K11020107). 


\section{References}

1. Kolb HJ, Schattenberg A, Goldman JM, Hertenstein B, Jacobsen N, Arcese W, Ljungman P, Ferrant A, Verdonck L, Niederwieser D, et al: Graft-versus-leukemia effect of donor lymphocyte transfusions in marrow grafted patients. Blood 86: 2041-2050, 1995.

2. Andersson BS, Kashyap A, Gian V, Wingard JR, Fernandez H, Cagnoni PJ, Jones RB, Tarantolo S, Hu WW, Blume KG, et al: Conditioning therapy with intravenous busulfan and cyclophosphamide (IV BuCy2) for hematologic malignancies prior to allogeneic stem cell transplantation: A phase II study. Biol Blood Marrow Transplant 8: 145-154, 2002.

3. Gill S and Porter DL: Reduced-intensity hematopoietic stem cell transplants for malignancies: Harnessing the graft-versus-tumor effect. Annu Rev Med 64: 101-117, 2013.

4. Keating MJ, O'Brien S, Lerner S, Koller C, Beran M, Robertson LE, Freireich EJ, Estey E and Kantarjian H: Long-term follow-up of patients with chronic lymphocytic leukemia (CLL) receiving fludarabine regimens as initial therapy. Blood 92: 1165-1171, 1998.

5. Iravani M, Evazi MR, Mousavi SA, Shamshiri AR, Tavakoli M, Ashouri A, Samiee S, Chahardovali B, Alimoghaddam K, Ghaffari SH and Ghavamzadeh A: Fludarabine and busulfan as a myeloablative conditioning regimen for allogeneic stem cell transplantation in high- and standard-risk leukemic patients. Bone Marrow Transplant 40: 105-110, 2007.

6. Pidala J, Kim J, Anasetti C, Kharfan-Dabaja MA, Nishihori T, Field T, Perkins J, Perez L and Fernandez HF: Pharmacokinetic targeting of intravenous busulfan reduces conditioning regimen related toxicity following allogeneic hematopoietic cell transplantation for acute myelogenous leukemia. J Hematol Oncol 3: 36, 2010.

7. Liu H, Zhai X, Song Z, Sun J, Xiao Y, Nie D, Zhang Y, Huang F, Zhou H, Fan Z, et al: Busulfan plus fludarabine as a myeloablative conditioning regimen compared with busulfan plus cyclophosphamide for acute myeloid leukemia in first complete remission undergoing allogeneic hematopoietic stem cell transplantation: A prospective and multicenter study. J Hematol Oncol 6: 15, 2013.

8. Chunduri S, Dobogai LC, Peace D, Saunthararajah Y, Quigley J, Chen YH, Mahmud N, Hurter E, Beri R and Rondelli D: Fludarabine/i.v. BU conditioning regimen: Myeloablative, reduced intensity or both? Bone Marrow Transplant 41: 935-940, 2008

9. Laport GG, Sandmaier BM, Storer BE, Scott BL, Stuart MJ, Lange T, Maris MB, Agura ED, Chauncey TR, Wong RM, et al: Reduced-intensity conditioning followed by allogeneic hematopoietic cell transplantation for adult patients with myelodysplastic syndrome and myeloproliferative disorders. Biol Blood Marrow Transplant 14: 246-255, 2008.

10. Lee JH, Joo YD, Kim H, Ryoo HM, Kim MK, Lee GW, Lee JH, Lee WS, Park JH, Bae SH, et al: Randomized trial of myeloablative conditioning regimens: Busulfan plus cyclophosphamide versus busulfan plus fludarabine. J Clin Oncol 31: 701-709, 2013.

11. Andersson BS, de Lima M, Thall PF, Wang X, Couriel D, Korbling M, Roberson S, Giralt S, Pierre B, Russell JA, et al: Once daily i.v. busulfan and fludarabine (i.v. Bu-Flu) compares favorably with i.v. busulfan and cyclophosphamide (i.v. BuCy2) as pretransplant conditioning therapy in AML/MDS. Biol Blood Marrow Transplant 14: 672-684, 2008.

12. Shimoni A, Hardan I, Shem-Tov N, Yeshurun M, Yerushalmi R, Avigdor A, Ben-Bassat I and Nagler A: Allogeneic hematopoietic stem-cell transplantation in AML and MDS using myeloablative versus reduced-intensity conditioning: The role of dose intensity. Leukemia 20: 322-328,2006.

13. Lee KH, Choi SJ, Lee JH, Lee JS, Kim WK, Lee KB, Sohn SK, Kim JG, Kim DH, Seol M, et al: Prognostic factors identifiable at the time of onset of acute graft-versus-host disease after allogeneic hematopoietic cell transplantation. Haematologica 90: 939-948, 2005

14. Filipovich AH, Weisdorf D, Pavletic S, Socie G, Wingard JR, Lee SJ, Martin P, Chien J, Przepiorka D, Couriel D, et al: National institutes of health consensus development project on criteria for clinical trials in chronic graft-versus-host disease: I. Diagnosis and staging working group report. Biol Blood Marrow Transplant 11: 945-956, 2005.
15. Jagasia MH, Greinix HT, Arora M, Williams KM, Wolff D, Cowen EW, Palmer J, Weisdorf D, Treister NS, Cheng GS, et al: National Institutes of Health consensus development project on criteria for clinical trials in chronic graft-versus-host disease: I. The 2014 Diagnosis and Staging Working Group report. Biol Blood Marrow Transplant 21: 389-401.e1, 2015.

16. Hughes WT, Armstrong D, Bodey GP, Bow EJ, Brown AE, Calandra T, Feld R, Pizzo PA, Rolston KV, Shenep JL and Young LS: 2002 Guidelines for the use of antimicrobial agents in neutropenic patients with cancer. Clin Infect Dis 34: 730-751, 2002.

17. McDonald GB, Slattery JT, Bouvier ME, Ren S, Batchelder AL, Kalhorn TF, Schoch HG, Anasetti C and Gooley T: Cyclophosphamide metabolism, liver toxicity, and mortality following hematopoietic stem cell transplantation. Blood 101: 2043-2048, 2003.

18. Slavin S, Nagler A, Naparstek E, Kapelushnik Y, Aker M, Cividalli G, Varadi G, Kirschbaum M, Ackerstein A, Samuel S, et al: Nonmyeloablative stem cell transplantation and cell therapy as an alternative to conventional bone marrow transplantation with lethal cytoreduction for the treatment of malignant and nonmalignant hematologic diseases. Blood 91: 756-763, 1998.

19. Giralt S, Thall PF, Khouri I, Wang X, Braunschweig I, Ippolitti C, Claxton D, Donato M, Bruton J, Cohen A, et al: Melphalan and purine analog-containing preparative regimens: Reduced-intensity conditioning for patients with hematologic malignancies undergoing allogeneic progenitor cell transplantation. Blood 97: 631-637, 2001.

20. Le Blanc K, Remberger M, Uzunel M, Mattsson J, Barkholt L and Ringdén $\mathrm{O}$ : A comparison of nonmyeloablative and reduced-intensity conditioning for allogeneic stem-cell transplantation. Transplantation 78: 1014-1020, 2004.

21. Niederwieser D, Maris M, Shizuru JA, Petersdorf E, Hegenbart U, Sandmaier BM, Maloney DG, Storer B, Lange T, Chauncey T, et al: Low-dose total body irradiation (TBI) and fludarabine followed by hematopoietic cell transplantation (HCT) from HLA-matched or mismatched unrelated donors and postgrafting immunosuppression with cyclosporine and mycophenolate mofetil (MMF) can induce durable complete chimerism and sustained remissions in patients with hematological diseases. Blood 101: 1620-1629, 2003.

22. Or R, Shapira MY, Resnick I, Amar A, Ackerstein A, Samuel S, Aker M, Naparstek E, Nagler A and Slavin S: Nonmyeloablative allogeneic stem cell transplantation for the treatment of chronic myeloid leukemia in first chronic phase. Blood 101: 441-445, 2003

23. Bornhauser M, Storer B, Slattery JT, Appelbaum FR, Deeg HJ, Hansen J, Martin PJ, McDonald GB, Nichols WG, Radich J, et al: Conditioning with fludarabine and targeted busulfan for transplantation of allogeneic hematopoietic stem cells. Blood 102: 820-826, 2003

24. Russell JA, Tran HT, Quinlan D, Chaudhry A, Duggan P, Brown C, Stewart D, Ruether JD, Morris D, Glick S, et al: Once-daily intravenous busulfan given with fludarabine as conditioning for allogeneic stem cell transplantation: Study of pharmacokinetics and early clinical outcomes. Biol Blood Marrow Transplant 8: 468-476, 2002

25. Chae YS, Sohn SK, Kim JG, Cho YY, Moon JH, Shin HJ, Chung JS, Cho GJ, Yang DH, Lee JJ, et al: New myeloablative conditioning regimen with fludarabine and busulfan for allogeneic stem cell transplantation: Comparison with $\mathrm{BuCy} 2$. Bone Marrow Transplant 40: 541-547, 2007.

26. Bredeson CN, Zhang MJ, Agovi MA, Bacigalupo A, Bahlis NJ, Ballen K, Brown C, Chaudhry MA, Horowitz MM, Kurian S, et al: Outcomes following HSCT using fludarabine, busulfan, and thymoglobulin: A matched comparison to allogeneic transplants conditioned with busulfan and cyclophosphamide. Biol Blood Marrow Transplant 14: 993-1003, 2008.

27. Alyea EP, Kim HT, Ho V, Cutler C, DeAngelo DJ, Stone R, Ritz J, Antin JH and Soiffer RJ: Impact of conditioning regimen intensity on outcome of allogeneic hematopoietic cell transplantation for advanced acute myelogenous leukemia and myelodysplastic syndrome. Biol Blood Marrow Transplant 12: 1047-1055, 2006

28. Martino R, Iacobelli S, Brand R, Jansen T, van Biezen A, Finke J, Bacigalupo A, Beelen D, Reiffers J, Devergie A, et al: Retrospective comparison of reduced-intensity conditioning and conventional high-dose conditioning for allogeneic hematopoietic stem cell transplantation using HLA-identical sibling donors in myelodysplastic syndromes. Blood 108: 836-846, 2006. 